\title{
Neutrophil-to-lymphocyte ratios in pregnant women with familial mediterranean fever
}

\author{
Keles $\mathrm{A}^{1}$, Iskender $\mathrm{D}^{2}$, Yucel Celik $\mathrm{O}^{1}$, Dagdeviren $\mathrm{G}^{1}$, Iskender $\mathrm{C}^{1}$, Caglar $\mathrm{AT}^{1}$, Celen $\mathrm{S}^{1}$ \\ University of Health Sciences Etlik Zübeyde Hanim Women's Health Care, Training \\ and Research Hospital, Ankara, Turkey. ayseistekdr@hotmail.com
}

\section{ABSTRACT}

OBJECTIVE: To investigate the association between maternal serum neutrophil-to-lymphocyte ratios (NLRs) and pregnancy outcomes in women with familial mediterranean fever (FMF).

BACKGROUND: FMF exists worldwide, it primarily affects Mediterranean countries

METHODS: We retrospectively analysed data from 269 pregnant women, who underwent a routine prenatal follow-up and delivery in our hospital from 2016 to 2020. Clinical and demographic data, including age, gravida, parity, abortus, proteinuria in the first trimester, NLR, obstetrical complications, gestational age at delivery, birthweight were retrieved from the patients' medical records. Data from 67 pregnant women with FMF and 202 healthy pregnant women were compared.

RESULTS: Patients with FMF showed higher rates of preeclampsia and primary caesarean delivery; however, there were no differences between the groups in terms of other obstetric complications or adverse neonatal outcomes. In both the FMF and control groups, NLRs in the third trimester were significantly higher than those in the first trimester. Additionally, patients in the FMF group demonstrated higher NLRs than patients in the control group in the third trimester.

CONCLUSIONS: The NLRS are a haematological parameter that can be used to predict subclinical inflammation and the effects of ongoing subclinical inflammation on the pregnancy outcomes in women with FMF (Tab. 4, Ref. 39). Text in PDF www.elis.sk

KEY WORDS: familial mediterranean fever, neutrophil-to-lymphocyte ratio, obstetrical complications, pregnancy, subclinical inflammation.

\section{Introduction}

Familial Mediterranean fever (FMF), an autoimmune disease characterized by recurrent inflammation of the serosa membranes, is prevalent among those living in the Mediterranean region (1, 2 ). Though this disease affects the population worldwide, it primarily affects Turks, Armenians, Arabs, and non-Ashkenazi Jews (3). The prevalence of FMF in Turkey is estimated to be between approximately $0.1 \%$ and $0.25 \%$ (4-6). In addition to the acute inflammation seen during the attacks, some patients exhibit a persistent subclinical inflammation (7-9). Long-term inflammation may cause chronic renal failure due to amyloidosis (10).

Studies examining the effects of FMF on women's health during the reproductive stage have shown that chronic recurrent serosa inflammation plays a role in the etiology of infertility (10). It is generally believed that FMF has a little impact on the preg-

'University of Health Sciences Etlik Zübeyde Hanim Women's Health Care, Training and Research Hospital, Ankara, Turkey, and ${ }^{2} \mathrm{Hematology}$ and Stem Cell Transplantation Clinic, Ankara Oncology Education and Research Hospital, Ankara, Turkey

Address for correspondence: A, Keles, MD, University of Health Sciences Etlik Zübeyde Hanim Women's Health Care, Training and Research Hospital, 06010 Ankara, Turkey

Phone: +90.532.5409066, Fax: +90.312.3238191 nancy outcomes $(3,11-15)$. The course of FMF during pregnancy is variable. While some patients have an attack-free period, others experience an increase in the frequency of attacks (10). Colchicine is effective in reducing FMF attacks, and continued treatment with colchicine is recommended during pregnancy and lactation without a reduction in dosage. The use of this drug during pregnancy has not been associated with teratogenesis or adverse pregnancy outcomes (1, 10, 16-18).

Systemic inflammation is associated with changes in the composition and quantity of circulating blood cells. Recent evidence suggests that measuring the ratios of blood cell components, such as the neutrophil-to-lymphocyte ratio (NLR), is a very sensitive but less specific hematologic parameter to measure stress, intensity of infection/inflammation $(19,20)$. NLR may have a prognostic significance for diseases associated with a chronic low-grade inflammation $(21,22)$. It has been stated that a high NLR is an indicator of inflammation and has a prognostic importance for these diseases (23-25).

In this study, we aimed to examine the relationship between NLR and maternal and neonatal outcomes of pregnant women with FMF followed in a tertiary hospital. We hypothesized that ongoing chronic subclinical inflammation in FMF would be reflected by an increased NLR, which could be used to predict adverse pregnancy outcomes. 


\section{Materials and methods}

This retrospective study examined pregnant women with FMF, who visited the Etlik Zübeyde Hanim Women's Health Practices \& Research Center from 2016 to 2020. FMF was diagnosed according to the Tel-Hashomer clinical criteria, which requires fulfilment of 2 major or 1 major and 2 minor criteria (26). Patients with pre-existing maternal diseases, such as diabetes mellitus, hypertension, connective tissue disease, inflammatory bowel disease, active infection, and allergic rhinitis, were not included in the study. Neutrophil and lymphocyte counts were obtained from complete blood counts taken during the first and third trimesters. All blood counts were measured in the same laboratory of the Etlik Zübeyde Hanim Gynecology Training and Research Hospital, and the data were retrospectively obtained from the hospital system. NLR was calculated by dividing the absolute neutrophil count by the absolute lymphocyte count. We excluded pregnant women lost to follow-up and those whose NLRs could not be calculated. Ultimately, data were analysed from 67 pregnant women with FMF (who met the criteria above) and from 202 healthy pregnant women without any systemic disease (who comprised the control group). The first and third trimester NLRs of the patients with active infection and labour were excluded. The presence of proteinuria was detected by a urine dipstick analysis. Medical records of the patients were reviewed, and the following data were obtained: maternal age, pre-pregnancy body mass index, total number of pregnancies, total number of births, total number of abortions, FMF duration, use of colchicine during pregnancy, presence of FMF attacks during pregnancy, pregnancy complications, congenital anomalies, gestational age at delivery, birth weight, 1- and 5-minute APGAR scores, and neonatal intensive care unit admission.

Preterm birth was defined as a birth that occurred before 37 weeks of gestation. Polyhydramnios was defined as an abnormally excessive amniotic fluid volume (deepest vertical pocket $>8 \mathrm{~cm}$ or amniotic fluid index $>24 \mathrm{~cm}$ ) at any point during the pregnancy. Oligohydramnios was defined as an abnormally small amount of amniotic fluid volume (deepest vertical pocket $<2 \mathrm{~cm}$ or amniotic fluid index $<5 \mathrm{~cm}$ ) at any point during the pregnancy. Intrauterine growth retardation was defined as an estimated newborn weight below the 10th percentile with Doppler abnormalities. Gestational hypertension was defined as persistent elevation of blood pressure above $140 / 90 \mathrm{mmHg}$ in at least 2 blood pressure measurements taken after the 20th week of pregnancy. Preeclampsia was defined as hypertension occurring after 20 weeks of gestation in a normotensive woman, with a significant proteinuria or thrombocytopenia or pulmonary oedema or abnormal liver enzymes or clinical symptoms such as: persistent headache or right upper quadrant pain. Gestational diabetes was defined as a single abnormal result from the 2-hour 75 -g oral glucose tolerance test or two abnormal results from the 3-hour 100-g oral glucose tolerance test. Preterm premature rupture of membranes was defined as the rupture of a membrane without labour before 37 weeks of gestation.

This study was approved by Medical Specialty Education Board of Etlik Zübeyde Hanim Women's Health Practices $\&$ Research Center with Decision Number: 7 and Dated May 14, 2020. Informed consent was obtained from all the patients, and all the data were anonymized. Statistical analysis was performed using SPSS software version 25 (Statistical Package for the Social Sciences, Chicago, IL). The Kolmogorov-Smirnov and ShapiroWilk tests were used to assess whether the data were distributed normally. Numerical variables with normal distribution are given as the means \pm standard deviations, and these values were compared using either the t-test or one-way ANOVA test. Comparisons of the groups with abnormally distributed numerical data were performed using the Mann-Whitney U test or the Kruskal-Wallis test. The chi-squared test and Fisher's exact test were used to compare categorical variables between the independent groups. The Wilcoxon signed-rank test was used to compare numerical data that were not normally distributed among dependent groups. A p-value of $<0.05$ was considered statistically significant.

\section{Results}

During the study period, 67 pregnant women diagnosed with FMF were evaluated. The prevalence of FMF among pregnant women in our hospital was $0.09 \%$. The total number of births during this period was approximately 71,000. One pregnancy from each group resulted in abortion. The clinical and demographic characteristics of the groups are shown in Table 1. Patients with FMF and patients in the control group were similar in terms of age, pre-pregnancy body mass index, and gravida. Patients with FMF exhibited a higher rate of in vitro fertilization (IVF) than patients in the control group. Protein presence in spot urine in the first trimester of pregnancy differed between the groups, with a higher rate of proteinuria in the patients with FMF. The average disease duration in patients with FMF was approximately 12 years, and $71.6 \%$ of the patients were taking colchicine. In $41 \%$ of the pregnant women with FMF, one or more attacks occurred during pregnancy.

Tab. 1. Characteristics of patients with FMF and control group.

\begin{tabular}{lccc}
\hline & FMF $(\mathrm{n}: 67)$ & Control (n:202) & $\mathrm{p}$ \\
\hline Age & $28.94 \pm 5.35$ & $28.40 \pm 5.56$ & $.48^{\mathrm{a}}$ \\
Body mass index & $24(19-34)$ & $26(19-37)$ & $.06^{\mathrm{b}}$ \\
Gravida & $3(1-10)$ & $2(1-6)$ & $.96^{\mathrm{b}}$ \\
Parity & $1(0-3)$ & $1(0-4)$ & $.03^{\mathrm{b}}$ \\
Abortus & $1(0-8)$ & $0(0-2)$ & $.03^{\mathrm{b}}$ \\
Abortus $\geq 2$ & $14(20.9 \%)$ & $13(6.9 \%)$ & $.001^{\mathrm{d}}$ \\
IVF pregnancy & $6(9 \%)$ & $3(1.5 \%)$ & $.009^{\mathrm{c}}$ \\
FMF duration & $11.90 \pm 5.88$ & - & - \\
Colchicine use during pregnancy & $48(71.6 \%)$ & - & - \\
Attacks during pregnancy & $28(41.8 \%)(\mathrm{p}=66)$ & - & - \\
Proteinuria in the first trimester & $8(11.9 \%)(\mathrm{p}=55)$ & $9(4.5 \%)$ & $.04^{\mathrm{c}}$ \\
Obstetrical complications & $17(25.4 \%)(\mathrm{p}=66)$ & $35(17.4 \%)$ & $.15^{\mathrm{d}}$ \\
\hline
\end{tabular}

IVF: In vitro fertilization, FMF: Familial Mediterranean Fever. ${ }^{a}$ independent $t$ test; ${ }^{b}$ Mann-Whitney $U$ test; 'Fisher's exact test; ‘Pearson ki kare 
Tab. 2. Comparison of pregnancy and neonatal outcomes in patients with FMF and control groups.

\begin{tabular}{lccc}
\hline & FMF (n:67) & Kontrol (n:202) & p \\
\hline Miscarriage & $1(1.5 \%)$ & $1(0.5 \%)$ & $.43^{\mathrm{b}}$ \\
Gestational diabetes mellitus $^{\mathrm{e}}$ & $7(10.6 \%)$ & $9(4.5 \%)$ & $.07^{\mathrm{b}}$ \\
Preterm delivery $^{\mathrm{e}}$ & $7(10.6 \%)$ & $10(5 \%)$ & $.14^{\mathrm{b}}$ \\
Preterm premature rupture of membranes $^{\mathrm{e}}$ & $4(6.1 \%)$ & $6(3 \%)$ & $.26^{\mathrm{b}}$ \\
Intrauterine growth restriction $^{\mathrm{e}}$ & $4(6.1 \%)$ & $15(7.5 \%)$ & $1^{\mathrm{b}}$ \\
Preeclampsia $^{\mathrm{b}}$ & $5(7.6 \%)$ & $4(2 \%)$ & $.04^{\mathrm{b}}$ \\
Olygohydroamnios $^{\mathrm{e}}$ & $1(1.5 \%)$ & $11(5.5 \%)$ & $.3^{\mathrm{b}}$ \\
Polyhydroamnios $^{\mathrm{e}}$ & 0 & $2(1 \%)$ & $1^{\mathrm{b}}$ \\
Caesarean delivery $^{\mathrm{e}}$ & $37(56.1 \%)$ & $92(45.8 \%)$ & $.14^{\mathrm{d}}$ \\
Primary caesarean delivery $_{\text {Gestational age at delivery }}^{\mathrm{e}}$ & $22(33.3 \%)$ & $41(20.4 \%)$ & $.03^{\mathrm{d}}$ \\
Birthweight (grams) $^{\mathrm{e}}$ & $39(29-41)$ & $39(26-42)$ & $.009^{\mathrm{c}}$ \\
NICU admission $^{\mathrm{e}}$ & $3154 \pm 608$ & $3244 \pm 524$ & $.24^{\mathrm{a}}$ \\
Fetal abnormality $^{\mathrm{e}}$ & $6(9.1 \%)$ & $8(4 \%)$ & $.11^{\mathrm{b}}$ \\
Obstetrical Complication $^{\mathrm{e}}$ & 0 & 0 & \\
First trimester NLR $^{\mathrm{e}}$ & $16(24.2 \%)$ & $35(17.4)$ & $.22^{\mathrm{d}}$ \\
Third trimester NLR $^{\mathrm{e}}$ & $3.24(0.06-7.14)$ & $3.18(0.80-7.39)$ & $.27^{\mathrm{c}}$ \\
\hline
\end{tabular}

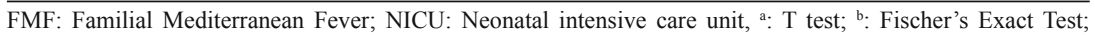
c: Mann-Whitney U test; ${ }^{\mathrm{d}}$ : Pearson chi square, ${ }^{\mathrm{e}}$ : Excluding miscarriage

Tab. 3. Comparison of certain clinical data in FMF patients according to colchicine use.

\begin{tabular}{lccc}
\hline & $\begin{array}{c}\text { Patient using } \\
\text { colchicine (n:48) }\end{array}$ & $\begin{array}{c}\text { Patient not using } \\
\text { colchicine (n:18) }\end{array}$ & $\mathrm{p}$ \\
\hline Gestational age at delivery & $39(29-41)$ & $38.5(33-41)$ & $.69^{\mathrm{c}}$ \\
Birthweight (grams) & $3160 \pm 663$ & $3140 \pm 452$ & $.90^{\mathrm{a}}$ \\
Attack during pregnancy & $21(43.8 \%)$ & $7(38.9 \%)$ & $.72^{\mathrm{d}}$ \\
Gestational diabetes mellitus $^{\mathrm{e}}$ & $3(6.3 \%)$ & $4(22.2)$ & $.08^{\mathrm{b}}$ \\
Preterm delivery $^{\mathrm{e}}$ & $5(10.4 \%)$ & $2(11.1 \%)$ & $1^{\mathrm{b}}$ \\
Preterm premature rupture of membranes $^{\mathrm{e}}$ & $2(4.2 \%)$ & $2(11.1 \%)$ & $.29^{\mathrm{b}}$ \\
Intrauterine growth restriction $^{\mathrm{e}}$ & $4(8.3 \%)$ & $3(16.7 \%)$ & $.38^{\mathrm{b}}$ \\
Preeclampsia $^{\mathrm{e}}$ & $4(8.3 \%)$ & $1(5.6)$ & $1^{\mathrm{b}}$ \\
Oligohydramnios $^{\mathrm{e}}$ & $1(2.1 \%)$ & 0 & $1^{\mathrm{b}}$ \\
Polyhydramnios $^{\mathrm{e}}$ & 0 & 0 & \\
Antenatal complications $^{\mathrm{e}}$ & $10(20.8 \%)$ & $6(33.3 \%)$ & $.34^{\mathrm{b}}$ \\
Primary Cesarean delivery $^{\mathrm{e}}$ & $14(29.2 \%)$ & $8(44.4 \%)$ & $.24^{\mathrm{d}}$ \\
Cesarean delivery $^{\mathrm{e}}$ & $21(43.8 \%)$ & $16(88.9 \%)$ & $.001^{\mathrm{d}}$ \\
NICU admission $^{\mathrm{e}}$ & $4(8.3 \%)$ & $2(11.1 \%)$ & $.66^{\mathrm{b}}$ \\
First trimester NLR $_{\text {Third trimester NLR }}^{\mathrm{e}}$ & $3.16(0.06-7.14)$ & $3.42(2.25-5.51)$ & $.64^{\mathrm{c}}$ \\
\hline Prit & $4.10(0.91-10.1)$ & $4.64(2.9-8.51)$ & $.08^{\mathrm{c}}$ \\
\hline
\end{tabular}

FMF: Familial Mediterranean Fever, NICU: neonatal intensive care unit, NLR: neutrophil to lymphocyte ratio. a: T test; ${ }^{\text {b: }}$ Fischer's Exact Test; c: Mann-Whitney U test; ${ }^{\text {d: }}$ Pearson chi square; ${ }^{\text {e }}$ : Excluding miscarriage

Tab. 4. Comparison of NLR data in FMF patients with or without antenatal complications and control groups.

\begin{tabular}{lccc}
\hline & $\begin{array}{c}\text { Control group with pregnancy } \\
\text { complications }^{\mathrm{b}}\end{array}$ & $\begin{array}{c}\text { FMF group with pregnancy com- } \\
\text { plications }^{\mathrm{b}}\end{array}$ & $\mathrm{p}$ \\
\hline First trimester NLR & $3.18(0.80-7.39)$ & $3.24(0.06-7.14)$ & $.27^{\mathrm{a}}$ \\
Third trimester NLR & $3.65(1.05-8.66)$ & $4.21(0.91-1010)$ & $.01^{\mathrm{a}}$ \\
\hline & $\begin{array}{c}\text { Control group without pregnancy } \\
\text { complications }^{\mathrm{b}}\end{array}$ & $\begin{array}{c}\text { FMF group without pregnancy } \\
\text { complications }\end{array}$ & \\
\hline First trimester NLR & $3.17(1.05-7.39)$ & $3.23(0.06-7.14)$ & $.60^{\mathrm{a}}$ \\
Third trimester NLR & $3.62(1.05-8.66)$ & $4.09(0.91-10.10)$ & $.07^{\mathrm{a}}$ \\
\hline
\end{tabular}

FMF: Familial Mediterranean Fever, NLR: neutrophil to lymphocyte ratio. ${ }^{\text {a }}$ : Mann-Whitney U test, ${ }^{\text {b: }}$ median (min-max)

Data regarding pregnancy and neonatal outcomes of the study patients are presented in Table 2. Preeclampsia and primary caesarean delivery rates were significantly higher in the FMF group than in the control group, while the gestational age at delivery was significantly lower, although the rates of preterm delivery were similar in both groups. There were no significant differences in obstetrical and neonatal outcomes between FMF patients, who did and did not receive colchicine during pregnancy. The only difference was a higher rate of caesarean deliveries in those who did not receive colchicine (Tab. 3).

The NLRs of patients in both groups are presented in Table 4. FMF patients with pregnancy complications exhibited higher NLRs in the third trimester than control patients with complications. FMF patients without obstetrical complications also showed higher NLRs than control group patients without obstetrical complications.

\section{Discussion}

The prevalence of FMF in pregnant women during the study period was $0.09 \%$. This was consistent with results from the previous studies $(5,6,27)$. Recurrent pregnancy loss is more common in pregnant women with FMF, and parity was higher in the control group. The rate of IVF pregnancies was significantly higher in FMF patients than in the control group patients. These findings, which were in agreement with those from previous studies, can be explained by the effects of existing subclinical inflammation and recurrent episodes of peritonitis on the genitourinary system (3, 13, 27).

Previous studies evaluating the relationship between FMF and pregnancy outcomes revealed conflicting results, although it was generally observed that FMF did not have a negative impact on obstetric and neonatal outcomes (11-14, 27). In our study, the rate of preeclampsia was significantly higher in pregnant women with FMF than in the control group patients. Similarly, proteinuria detected in the first trimester was significantly higher in patients with FMF than in the control group patients. While differing results were obtained in two previous studies evaluating the relationship between basal proteinuria level and pregnancy complications in pregnant women with FMF, our study showed that the presence of proteinuria in first trimester spot urine might be effective in predicting preeclampsia in these patients $(13,27)$.

The relationship between FMF and preterm delivery has also been frequently evaluated previously. It has been reported that subclinical inflammation and recurrent episodes of peritonitis 


\section{1-255}

seen in FMF may cause preterm labour by triggering uterine contractions. It may also increase iatrogenic preterm delivery by mimicking pregnancy complications $(10,18,28)$. Other studies showed that FMF did not increase the risk of preterm birth (13, 27). In the present study, the preterm delivery rates were similar in the FMF and the control groups. Gestational age at delivery, however, was significantly lower in FMF patients than in the control group patients. FMF patients did not display increased rates of other obstetric complications, with the exception of a higher primary caesarean delivery rate. Although this data is consistent with data from literature, this cannot be completely attributed to FMF; it may be due to physicians' more liberal approach to caesarean delivery owing to concerns about the disease $(17,28,29)$.

In the present study, obstetrical and neonatal outcomes were similar in FMF patients, who received colchicine therapy during pregnancy and those who did not. A recent meta-analysis found that the use of colchicine during pregnancy may cause an increased risk of pre-term birth and low birth weight, but it was also emphasized that these results might be related to the natural course of FMF (16). There were no differences in the terms of neonatal outcomes between the FMF and the control groups in our study. Although our data is consistent with data from two recent studies, other previous studies have reported FMF in pregnancy to be associated with low birth weight $(13,16,27,29)$.

NLR, a simple and easy-to-apply marker obtained from a complete blood count, is a relatively new parameter used in the evaluation of inflammation (30). Several studies evaluated the relationship between NLR and chronic inflammation. Similarly, NLR has been investigated in non-pregnant FMF patients, particularly during attacks $(24,31-34)$. Increased NLRs have been previously linked with pregnancy complications, such as gestational diabetes, preeclampsia, preterm birth, and intrahepatic cholestasis (35-38). To the best of our knowledge, our study is the first to evaluate the effects of NLR on pregnancy outcomes in women with FMF. In our study, no significant relationship was found between the pregnancy complications and NLR in either pregnant women with FMF or in the control group. In both groups, NLRs were significantly higher in the third trimester than in the first trimester. Furthermore, patients in the FMF group with pregnancy complications demonstrated higher third trimester NLRs than those in the control group. During pregnancy, leukocyte counts tend to increase, particularly in the neutrophil component. This increase is higher in the third trimester than in the other two (39). It is therefore plausible to deduce that the increased third trimester NLRs in both groups of patients were due to the physiological neutrophilia of pregnancy. However, the higher third trimester NLRs in patients with FMF compared to those of the control group patients may be due to ongoing subclinical inflammation.

The primary limitations of this study were its retrospective design and relatively small sample size. The low number of cases of FMF and the low number of obstetric complications in this group prevented us from determining potential associations that might exist between NLR and perinatal outcomes. Future studies with larger samples sizes are necessary to clarify this potential association.
In conclusion, while NLR is an easy and inexpensive parameter used in the evaluation of subclinical inflammation, the present study found the association between NLR and subclinical inflammation on pregnant women with FMF. However, we believe that pregnancy complications can be predicted in women with FMF by using inflammatory markers in addition to NLR.

\section{References}

1. Ben-Chetrit E, Levy M. Familial mediterranean fever. The Lancet 1998; 351 (9103): 659-664.

2. Touitou I. The spectrum of Familial Mediterranean Fever (FMF) mutations. Eur J Human Genet 2001; 9 (7): 473-483.

3. Ben-Chetrit E, Ben-Chetrit A, Berkun Y, Ben-Chetrit E. Pregnancy outcomes in women with familial Mediterranean fever receiving colchicine: is amniocentesis justified? Arthritis Care Res 2010; 62 (2): $143-148$.

4. Levy M, Ehrenfeld M, Levo Y, Fischel R, Zlotnick A, Eliakim M. Circulating immune complexes in recurrent polyserositis. (Familial mediterranean fever, periodic disease). J Rheum 1980; 7 (6): 886-890.

5. Tunca M, Akar S, Onen F et al. Familial Mediterranean fever (FMF) in Turkey: results of a nationwide multicenter study. Medicine 2005; 84 (1): $1-11$.

6. Cobankara V, Fidan G, Türk T, Zencir M, Colakoglu M, Ozen S. The prevalence of familial Mediterranean fever in the Turkish province of Denizli: a field study with a zero patient design. Clin Exp Rheum 2004; 22 (4 Suppl 34): S27-30.

7. Ben-Zvi I, Livneh A. Chronic inflammation in FMF: markers, risk factors, outcomes and therapy. Nat Rev Rheum 2011; 7 (2): 105-112.

8. Colak B, Gurlek B, Yegin ZA et al. The relationship between the MEFV genotype, clinical features, and cytokine-inflammatory activities in patients with familial mediterranean fever. Renal Failure 2008; 30 (2): 187-191.

9. Lachmann H, Şengül B, Yavuzşen T et al. Clinical and subclinical inflammation in patients with familial Mediterranean fever and in heterozygous carriers of MEFV mutations. Rheumatology 2006; 45 (6): $746-750$.

10. Ben-Chetrit E, Levy M. Reproductive system in familial Mediterranean fever: an overview. Ann Rheum Dis 2003; 62 (10): 916-929.

11. Diav-Citrin O, Shechtman S, Schwartz V et al. Pregnancy outcome after in utero exposure to colchicine. Am J Obstet Gynecol 2010; 203 (2): 144.e1-6.

12. Nabil H, Zayed A, State O, Badawy A. Pregnancy outcome in women with familial Mediterranean fever. J Obstet Gynaec 2012; 32 (8): 756-759.

13. Yasar O, Iskender C, Kaymak O, Taflan Yaman S, Uygur D, Danisman N. Retrospective evaluation of pregnancy outcomes in women with familial Mediterranean fever. The journal of maternal-fetal \& neonatal medicine : the official journal of the European Association of Perinatal Medicine, the Federation of Asia and Oceania Perinatal Societies, the International Society of Perinatal Obstet 2014; 27 (7): 733-736.

14. Yazicioglu A, Turgal M, Yucel OS, Ozyuncu O, Beksac MS. Pregnancy outcome in women with familial mediterranean fever: a retrospective analysis of 50 cases with a 10-year experience 2014.

15. Karakas Yilmaz N, Kara M, Kaba M, Coskun B, Erkiline S, Erkaya S. Effect of Familial Mediterranean Fever on Ivf Outcome: A Retrospective Case Series. Acta Clin Croatica 2016; 55 (2): 254-258. 
16. Indraratna PL, Virk S, Gurram D, Day RO. Use of colchicine in pregnancy: a systematic review and meta-analysis. Rheumatology 2018; 57 (2): 382-387.

17. Rabinovitch O, Zemer D, Kukia E, Sohar E, Mashiach S. Colchicine treatment in conception and pregnancy: two hundred thirty-one pregnancies in patients with familial Mediterranean fever. American journal of reproductive immunology (New York, NY: 1989) 1992; 28 (3-4): 245-246.

18. Mijatovic V, Hompes PG, Wouters MG. Familial Mediterranean fever and its implications for fertility and pregnancy. Eur J Obstet Gynecol Reprod Biol 2003; 108 (2): 171-176.

19. Zahorec R. Ratio of neutrophil to lymphocyte counts--rapid and simple parameter of systemic inflammation and stress in critically ill. Bratisl Lek Listy $2001 ; 102$ (1): 5-14.

20. Zahorec R. Neutrophil-to-lymphocyte ratio. Sixteen-year-long history since publication of our article in Bratislava Medical Journal. Bratisl Med J 2017; 118 (6): 321-323.

21. Núñez J, Núñez E, Bodí V et al. Usefulness of the neutrophil to lymphocyte ratio in predicting long-term mortality in ST segment elevation myocardial infarction. Amer J Cardiol 2008; 101 (6): 747-752.

22. Balta S, Demirkol S, Celik T et al. Association between coronary artery ectasia and neutrophil-lymphocyte ratio. Angiology 2013; 64 (8): $627-632$.

23. Afari ME, Bhat T. Neutrophil to lymphocyte ratio (NLR) and cardiovascular diseases: an update. Exp Rev Cardiovasc Ther 2016; 14 (5): $573-577$.

24. Ahsen A, Ulu MS, Yuksel S et al. As a new inflammatory marker for familial Mediterranean fever: neutrophil-to-lymphocyte ratio. Inflammation 2013; 36 (6): 1357-1362.

25. Kelesoglu FM, Aygun E, Okumus NK et al. Evaluation of subclinical inflammation in familial Mediterranean fever patients: relations with mutation types and attack status: a retrospective study. Clin Rheum 2016; 35 (11): 2757-2763.

26. Livneh A, Langevitz $\mathbf{P}$, Zemer $\mathbf{D}$ et al. Criteria for the diagnosis of familial Mediterranean fever. Arthritis Rheum 1997; 40 (10): 1879-1885.

27. Iskender D, Kara O, Ozturk Kaymak A et al. Association between basal proteinuria levels and pregnancy outcomes in familial Mediterranean fever. J Obstet Gynaec 2020: 1-4.

28. Ofir D, Levy A, Wiznitzer A, Mazor M, Sheiner E. Familial Mediterranean fever during pregnancy: an independent risk factor for preterm delivery. Eur J Obstet Gynecol Reprod Biol 2008; 141 (2): 115-118.
29. Yucel A, Sanhal CY, Daglar K, Kara O, Uygur D, Erel O. Thiol/ disulphide homeostasis in pregnant women with Familial Mediterranean fever. Redox Report 2016; 21 (6): 287-291.

30. Kucuk A, Uslu AU, Ugan Y et al. Neutrophil-to-lymphocyte ratio is involved in the severity of ankylosing spondylitis. Bratisl Med J 2015; 116 (12): 722-725.

31. Okyay GU, İnal S, Öneç K et al. Neutrophil to lymphocyte ratio in evaluation of inflammation in patients with chronic kidney disease. Renal Failure 2013; 35 (1): 29-36.

32. Imtiaz F, Shafique K, Mirza SS, Ayoob Z, Vart P, Rao S. Neutrophil lymphocyte ratio as a measure of systemic inflammation in prevalent chronic diseases in Asian population. Internat Arch Med 2012; 5 (1): 2 .

33. Uluca Ü, Ece A, Şen V et al. Usefulness of mean platelet volume and neutrophil-to-lymphocyte ratio for evaluation of children with Familial Mediterranean fever. Medical Science Monitor: Internat Med J Exp Clin Res 2014; 20: 1578.

34. Özişler C. Ailesel Akdeniz Ateşi Tanili Hastalarda Atak ve Atak Dişi Dönemlerdeki Nötrofil-Lenfosit Orani ve Ortalama Trombosit Hacminin Değerlendirilmesi. Türk Klin Tip Bilimleri Dergisi 2019; 39 (2): $179-186$.

35. Oylumlu M, Ozler A, Yildiz A et al. New inflammatory markers in pre-eclampsia: echocardiographic epicardial fat thickness and neutrophil to lymphocyte ratio. Clin Exp Hypertension 2014; 36 (7): 503-507.

36. Mannaerts D, Heyvaert S, De Cordt C, Macken C, Loos C, Jacquemyn Y. Are neutrophil/lymphocyte ratio (NLR), platelet/lymphocyte ratio (PLR), and/or mean platelet volume (MPV) clinically useful as predictive parameters for preeclampsia? J Maternal-Fetal Neonat Med 2019; 32 (9): 1412-1419.

37. Kim MA, Lee BS, Park YW, Seo K. Serum markers for prediction of spontaneous preterm delivery in preterm labour. Eur J Clin Invest 2011; 41 (7): 773-780.

38. Akkar OB, Sancakdar E, Karakus $S$ et al. Evaluation of maternal serum 25-hydroxyvitamin D, paraoxonase 1 levels, and neutrophil-tolymphocyte ratio in spontaneous preterm birth. Internat Med J Exp Clin Res $2016 ; 22: 1238$.

39. Efrati P, Presentey B, Margalith M, Rozenszajn L. Leukocytes of normal pregnant women. Obstet Gynecol 1964; 23 (3): 429-432.

Received September 29, 2020.

Accepted November 3, 2020. 